\title{
Cell-Type-Dependent Molecular Composition of the Axon Initial Segment
}

\author{
Andrea Lorincz and Zoltan Nusser \\ Laboratory of Cellular Neurophysiology, Institute of Experimental Medicine, Hungarian Academy of Sciences, 1083 Budapest, Hungary
}

The exact site of initiation and shape of action potentials vary among different neuronal types. The reason for this variability is largely unknown, but the subunit composition, density and distribution of voltage-gated sodium (Nav) and potassium (Kv) channels within the axon initial segment (AIS) are likely to play a key role. Here, we asked how heterogeneous are the density and distribution of Nav and Kv channels within the AISs of a variety of excitatory and inhibitory neurons. Most of the studied cell types expressed a high density of Nav1.6, Kv1.1, and Kv1.2 subunits in their AIS, but the Nav1.1 subunit could only be detected in GABAergic interneurons. A proximodistal gradient in the density of these subunits was observed within the AIS of certain nerve cells but not in others. For example, a gradual increase of the Nav1.6 subunit was observed in cortical layer 2/3 and hippocampal CA1 pyramidal cell (PC) AISs, whereas its density was rather uniform in layer 5 PC AISs. The Nav1.1 subunit was distributed evenly along the AIS of short-axon cells of the main olfactory bulb but was restricted to the proximal part of the AIS in cortical and cerebellar interneurons. Our results reveal a cell type-dependent expression of sodium and potassium channel subunits with varying densities along the proximo-distal axis of the AISs. This precise arrangement is likely to contribute to the diversity of firing properties observed among central neurons.

Key words: voltage-gated ion channels; immunohistochemistry; axon initial segment; cortex; hippocampus; cerebellum; olfactory bulb

\section{Introduction}

The axon initial segment (AIS) is a structurally and functionally specialized region of the axon believed to be critical for the generation of action potentials (APs). Electrophysiological and imaging experiments have shown that the exact location of the axonal AP initiation varies in a cell type-dependent manner, ranging from the proximal axon in dentate gyrus granule cells (Kole et al., 2008; Schmidt-Hieber et al., 2008) through the distal AIS in cortical layer 5 PCs (Palmer and Stuart, 2006; Kole et al., 2007; Shu et al., 2007) and CA3 PCs (Meeks and Mennerick, 2007) to the first node of Ranvier in cerebellar Purkinje cells (Clark et al., 2005). Similarly, the shape of the AP and the firing properties differ considerably among various types of neurons (for review, see Bean, 2007). This diversity is likely to be the consequence of cell type-dependent differences in the molecular organization of the site of AP initiation, such as the subunit composition, density and distribution of voltage-gated sodium (Nav) and potassium (Kv) channels. High density of Nav channels at the AIS (Kole et al., 2008) lowers the threshold for AP initiation

\footnotetext{
Received 0ct. 8, 2008; revised Nov. 11, 2008; accepted Nov. 13, 2008.

This work was supported by a European Commission Integrated Project grant (EUSynapse Project; LSHM-CT2005-019055 to A.L., Z.N.). A.L. is the recipient of a János Bolyai Scholarship of the Hungarian Academy of Sciences. Z.N. is the recipient of a Wellcome Trust Project grant and a European Young Investigator Award (www.esf.org/ euryi). We thank Drs. Bruce L. Tempel and Carol A. Robbins for kindly providing the Kv1.1 ${ }^{-1-}$ and Kv1.2 $2^{-1-}$ mice brains; Dr. Jean-Marc Fritschy for the anti-GABA $\mathrm{R} \alpha 1$ antibody; and Dr. Mark D. Eyre for his comments on this manuscript.

Correspondence should be addressed to either of the following: Andrea Lorincz or Zoltan Nusser, Laboratory of Cellular Neurophysiology, Institute of Experimental Medicine, Hungarian Academy of Sciences, Szigony Street 43, 1083 Budapest, Hungary, E-mail: lorincz@koki.hu or nusser@koki.hu.

DOI:10.1523/JNEUROSCI.4833-08.2008

Copyright $\odot 2008$ Society for Neuroscience $\quad 0270-6474 / 08 / 2814329-12 \$ 15.00 / 0$
}

and gives rise to a fast, regenerative inward current during the rising phase of the depolarization, and in the nodes of Ranvier it ensures the efficient AP conduction. Voltage-gated $\mathrm{K}^{+}$channels are key regulators of AP repolarization, firing rate and pattern.

Individual neurons express several $\mathrm{Nav}$ and $\mathrm{Kv}$ subunits, paralleling the wide range of functional requirements they must fulfill. Loss or mutations of Nav1.1 (Yu et al., 2006), Nav1.2 (Planells-Cases et al., 2000), Nav1.6 (Meisler et al., 2004), Kv1.1 (Smart et al., 1998), or Kv1.2 (Brew et al., 2007) subunits cause epileptic seizures, motor dysfunctions, impairments in AP generation and often premature death, suggesting that these subunits are vital for AP generation and propagation. Therefore, revealing the precise subcellular distribution of these subunits will help to understand their contribution to the output generation of different neurons.

The AIS is well equipped to anchor and cluster Nav channels, particularly the Nav1.6 subunit, at high densities by cytoskeletal proteins (Ankyrin-G, $\beta$ IV spectrin) and cell adhesion molecules (CAMs, Neurofascin-186) (Jenkins and Bennett, 2001; Hedstrom et al., 2007; Yang et al., 2007). Kv1 channels have been localized to distinct axonal compartments. Electrophysiological experiments identified Kv1 subunit-mediated currents in synaptic terminals (Geiger and Jonas, 2000; Southan and Robertson, 2000). Immunohistochemical studies revealed the presence of Kv1.1 and Kv1.2 subunits in the juxtaparanodal regions of nodes of Ranvier and in the cerebellar pinceau (Rhodes et al., 1997). The Kv1.2 subunit has been recently described at the AIS of retinal ganglion cells (Van Wart et al., 2007) and human cortical layer 5 PCs (Inda et al., 2006).

Here, with the help of an antigen retrieval method, we determined the distribution of the Nav1.1, Nav1.6, Kv1.1, and Kv1.2 
subunits in the AISs of different neurons in the neocortex, hippocampus, main olfactory bulb (MOB) and cerebellum. The efficient detection of these subunits in the AISs required the application of this antigen retrieval method, enabling the discovery of their cell type-dependent expression and polarized distribution in the AISs.

\section{Materials and Methods}

Tissue preparation. Adult male Wistar rats and Kv1.1 ${ }^{+/+}, \mathrm{Kv1.1} 1^{-/-}$ (P35), Kv1.2 $2^{+/+}$, and Kv1.2 $2^{-/-}$mice (P16; a generous gift from Prof. B. L. Tempel, University of Washington, Seattle, WA) were deeply anesthetized with ketamine and xylazine. They were perfused through the aorta, first with $0.9 \%$ saline for $1 \mathrm{~min}$, then with ice-cold fixative containing $4 \%$ paraformaldehyde and $15 \mathrm{v} / \mathrm{v} \%$ picric acid in $0.1 \mathrm{~m}$ phosphate buffer $(\mathrm{PB}, \mathrm{pH}=7.3)$ for $15 \mathrm{~min}$. Then, $60-\mu \mathrm{m}$-thick sections from the MOB, forebrain and cerebellum were cut with a Vibratome (VT1000S, Leica Microsystems) and washed overnight in $0.1 \mathrm{M} \mathrm{PB}$.

Fluorescence immunohistochemistry. Sections were treated with 0.2 $\mathrm{mg} / \mathrm{ml}$ pepsin (Cat. No.: S3002; Dako) in $0.2 \mathrm{M} \mathrm{HCl}$ at $37^{\circ} \mathrm{C}$ for $10-15$ min and were washed in $0.1 \mathrm{M} \mathrm{PB}$ similar to the procedure developed by Watanabe et al. (1998). Immunofluorescent reactions were performed as described previously (Lörincz et al., 2002, 2007). Sections were blocked in normal goat serum (NGS, 10\%) made up in Tris-buffered saline (TBS, $\mathrm{pH}=7.4$ ), followed by incubations in primary antibodies diluted in TBS containing $2 \% \mathrm{NGS}$ and $0.1 \%$ Triton $\mathrm{X}-100$. The following primary antibodies were used in this study: rabbit anti-Nav1.1 (1:100; Millipore), mouse anti-Nav1.1 (K74/71; 1:250; NeuroMab, University of California, Davis, Davis, CA), rabbit anti-Nav1.6 (Nav1.6-R, 1:100; Alomone Labs), mouse anti-Nav1.6 (Nav1.6-M, K87A/10; 1:500; NeuroMab), mouse anti-Kv1.1 (K36/15; 1:1000; NeuroMab), mouse anti-Kv1.2 (K14/16; 1:500; NeuroMab), mouse anti-AnkyrinG (1:100, Santa Cruz Biotechnology), mouse anti-pan-Neurofascin (L11A/41; 1:1000; NeuroMab), guinea pig anti-GABA $A_{\mathrm{A}}$ receptor $\alpha 1$ subunit (1:1000; a gift from Prof. J.-M. Fritschy, University of Zurich, Zurich, Switzerland) and mouse anti-parvalbumin (PV; 1:1000; Swant). Following several washes in TBS, the following secondary antibodies were used to visualize the immunoreactions: Alexa488 conjugated goat anti-rabbit (1:500; Invitrogen), Cy3 conjugated goat anti-mouse (1:500, Jackson ImmunoResearch), Cy3 conjugated goat anti-guinea pig (1:500, Jackson) and Cy5 conjugated goat anti-rabbit (1:500; Jackson). Sections were then mounted on slides in Vectashield (Vector Laboratories).

Images were taken with a confocal laser scanning microscope (FV1000, Olympus) using a $20 \times(\mathrm{NA}=0.85)$ or a $60 \times(\mathrm{NA}=1.35)$ objective. Automated sequential acquisition of multiple channels was used. For low-magnification images, $z$-stack images were collected; 3-5 images at $0.5 \mu \mathrm{m}$ from the neocortex and hippocampus and 13-17 consecutive images from the MOB and the cerebellum at $1 \mu \mathrm{m}$. For highmagnification images, single confocal images or maximum intensity $z$-projection images were used (2-3 confocal images at 0.3-0.5 $\mu \mathrm{m}$ ).

Control experiments. No labeling was observed when the primary antibodies were omitted from the reactions. The lack of cross-reactivity of the secondary antibodies in double- and triple-labeling experiments was consistently checked. Specificity of the immunosignal obtained with the anti-Kv1.1 and Kv1.2 antibodies was tested on brain slices obtained from $\mathrm{Kv1}_{1}{ }^{-1-}$ and Kv1.2 ${ }^{-1-}$ mice, respectively (Smart et al., 1998; Brew et al., 2007; Lorincz and Nusser, 2008). Specificity of the immunoreactions for the Nav1.1 and Nav1.6 subunits was tested in double-labeling experiments using anti-Nav1.1 and anti-Nav1.6 antibodies raised against different, nonoverlapping epitopes. The rabbit polyclonal anti-Nav1.6 antibody (Nav1.6-R) was raised against an epitope (amino acids 10421061) corresponding to a sequence in the intracellular loop between domains II and III. The mouse monoclonal anti-Nav1.6 antibody (Nav1.6-M) was generated against an epitope in the intracellular loop between domains I and II (amino acids 459-476) of the rat Nav1.6 subunit. The rabbit polyclonal anti-Nav1.1 antibody (Nav1.1-R) was raised against amino acids 465-481 of the rat Nav1.1 subunit, corresponding to a sequence in the intracellular loop between domain I and II. The mouse monoclonal anti-Navl.1 antibody (Nav1.1-M) was raised against the $\mathrm{C}$ terminus of the rat Nav1.1 subunit (amino acids 1929-2009).

\section{Results}

Specificity of immunoreactions for the Kv1.1, Kv1.2, Nav1.1, and Nav1.6 subunits

First, we evaluated the specificity of light microscopic (LM) immunofluorescent reactions on perfusion fixed brain sections using anti-Kv1.1, Kv1.2, Nav1.1, and Nav1.6 subunit antibodies. Conventional immunofluorescent reactions revealed only cytoplasmic labeling for the Kv1.1 subunit in scattered cells in the neocortex, hippocampus and MOB of Kv1.1 ${ }^{+/+}$mice (Fig. 1). The entire labeling disappeared in brain slices obtained from Kv1.1 ${ }^{-/-}$mice, demonstrating that all immunosignal was the result of a specific antibody-Kv1.1 subunit interaction. However, when we applied an antigen retrieval method (digestion with pepsin at $37^{\circ} \mathrm{C}$ for $10-15 \mathrm{~min}$ ), an additional intense labeling appeared in elongated, AIS-like processes in the neuropil of the neocortex (Fig. $1 A$, right), hippocampus (Fig. $1 B, C$, right) and MOB (Fig. $1 D$, right), which also completely disappeared in the Kv1.1 ${ }^{-1-}$ mice. Without antigen retrieval, only neuropil labeling was observed for the Kv1.2 subunit in the neocortex, hippocampus and MOB (supplemental Fig. 1, available at www.jneurosci.org as supplemental material), which all disappeared in brain slices obtained from $\mathrm{Kv}_{1.2} 2^{-1-}$ mice (supplemental Fig. 1, available at www.jneurosci.org as supplemental material). Pepsin treatment revealed an additional, intense labeling of AIS-like processes in all examined areas (supplemental Fig. 1, available at www.jneurosci.org as supplemental material), which also vanished in $\mathrm{Kv} 1.2^{-1-}$ mice. The immunolabeling for the Kv1.1 and Kv1.2 subunits in control mice was identical to that observed in Wistar rats. These findings suggest that without antigen retrieval, ion channels in the AIS may be inaccessible to the antibodies, which is likely to be the consequence of masking the epitopes by a dense macromolecular matrix comprised of cytoskeletal proteins and/or cell adhesion molecules. However, in a different subcellular microenvironment, the same antigen might be easily accessible to the antibodies (Lorincz and Nusser, 2008). Indeed, using the same antibodies, we detected the previously reported (Rhodes et al., 1997) strong immunolabeling for the Kv1.1 (Fig. $1 E$ ) and Kv1.2 (supplemental Fig. $1 E$, available at www. jneurosci.org as supplemental material) subunits in cerebellar pinceau (the axonal plexus formed by basket cell axons around the Purkinje cell AIS) without pepsin treatment, demonstrating that epitopes can be obscured in a cell type- and subcellular compartment-dependent manner.

Next, we tested the specificity of the Nav1.1 and Nav1.6 subunit immunoreactions by performing double-labeling experiments using two antibodies raised against different, nonoverlapping epitopes of the Nav1.1 (Nav1.1-R and Nav1.1-M) and Nav1.6 (Nav1.6-R and Nav1.6-M) subunits (see Materials and Methods). The identical labeling pattern achieved in doublelabeling experiments on pepsin-treated sections verified the specificity of the immunosignal for the Nav1.1 (supplemental Fig. 2C, available at www.jneurosci.org as supplemental material) and Nav1.6 (Fig. 2A; supplemental Fig. 2A,B, available at www. jneurosci.org as supplemental material) subunits. Similar to our findings for the potassium channel subunits, immunolabeling of the AISs for the Nav1.1 or Nav1.6 subunits was only observed following pepsin treatment. In the rest of the experiments, the Nav1.1-M and the Nav1.6-R antibodies were used, because they provided a more intense immunosignal. Multiple labeling exper- 


\section{No pepsin}

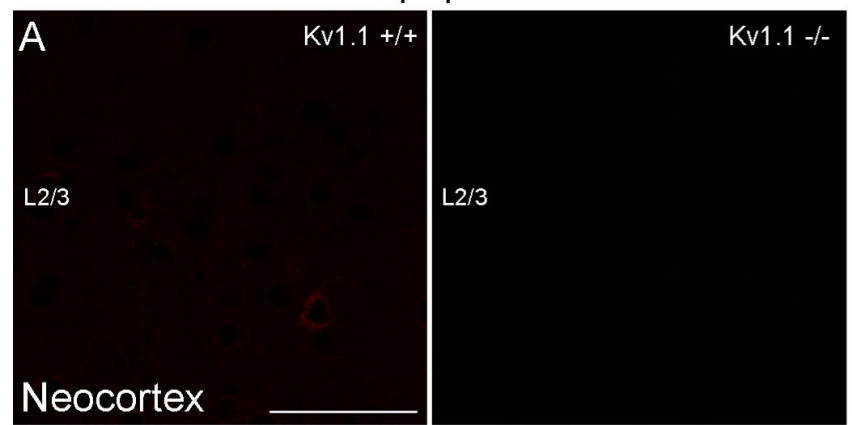

B

sr

sp

\section{CA1}

C

sr

sl

$\mathrm{sp}$

\section{CA3}

$\mathrm{D}$

$\mathrm{gl}$

epl

$\mathrm{mcl}$

gcl

\section{MOB}

E

$\mathrm{m}$

$\mathrm{pcl}$

gcl

Cerebellum

\section{Pepsin treated}

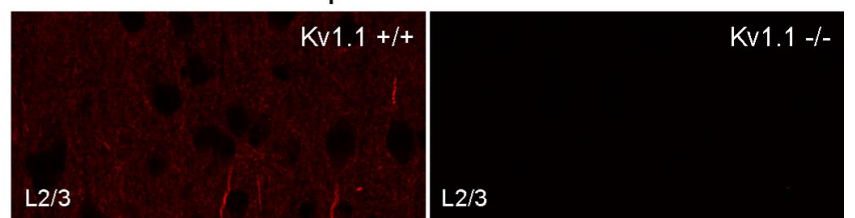

$L 2 / 3$

sr

$\mathrm{sp}$
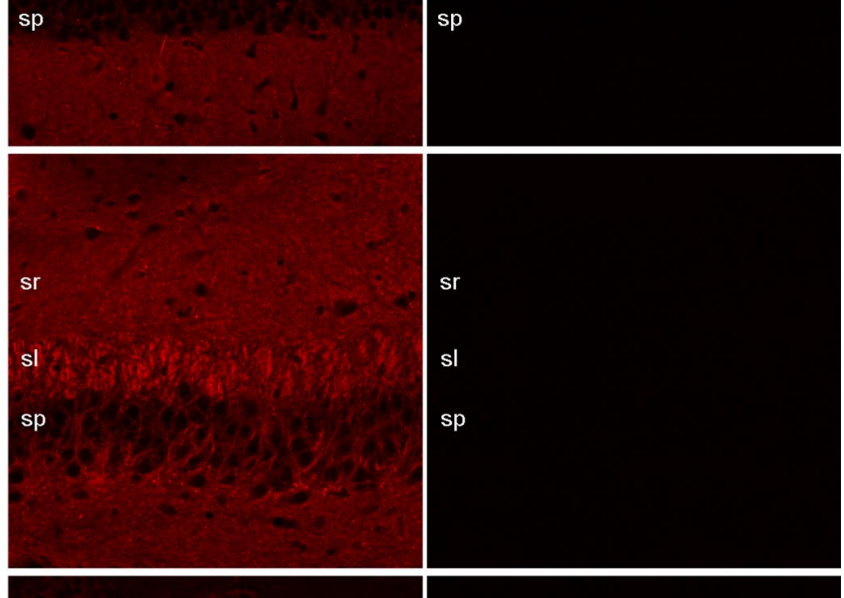

gl

gl

epl

$\mathrm{mcl}$

$\mathrm{gcl}$

gc

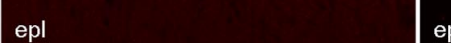

$\mathrm{mc}$

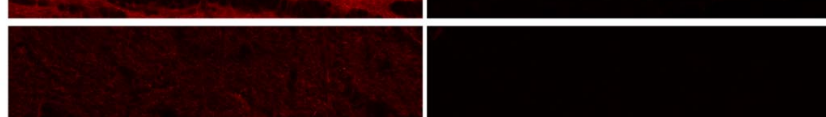

$\mathrm{ml}$

$\mathrm{m}$

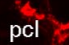

pc

gcl

$\mathrm{gc}$

Figure 1. Testing the specificity of Kv1.1 subunit immunolabeling on conventional and pepsin-treated brain sections using Kv1.1 ${ }^{-/-}$mice. $\boldsymbol{A}-\boldsymbol{D}$, Without pepsin treatment, a faint neuropil or cytoplasmic labeling in scattered cells is detected in the neocortex ( $\boldsymbol{A}$, left), CA1 (B, left), and CA3 ( $\boldsymbol{C}$, left) areas of the hippocampus and in the M0B (D, left) obtained from Kv1.1 ${ }^{+/+}$mice, and all labeling disappears in Kv1.1 ${ }^{-/-}$mice. After pepsin treatment, the cytoplasmic labeling of scattered nerve cells is not observed, but the neuropil labeling became more pronounced and intensely labeled AISs appear (A-D, right). In Kv1.1 ${ }^{-/-}$mice, all immunosignals disappear. $\boldsymbol{E}$, In the cerebellar cortex, the pinceau is strongly immunopositive for the Kv1.1 subunit with and without pepsin treatment. The specificity of immunosignal is proven by the lack of labeling in Kv1.1 ${ }^{-/-}$mice. Images from Kv1.1 ${ }^{+/+}$and Kv1.1 ${ }^{-/-}$sections were acquired with identical settings (e.g., PMT voltage, laser intensity) of the confocal microscope. Within each panel, all images are at the same magnification. Scale bars, $50 \mu \mathrm{m}$. 

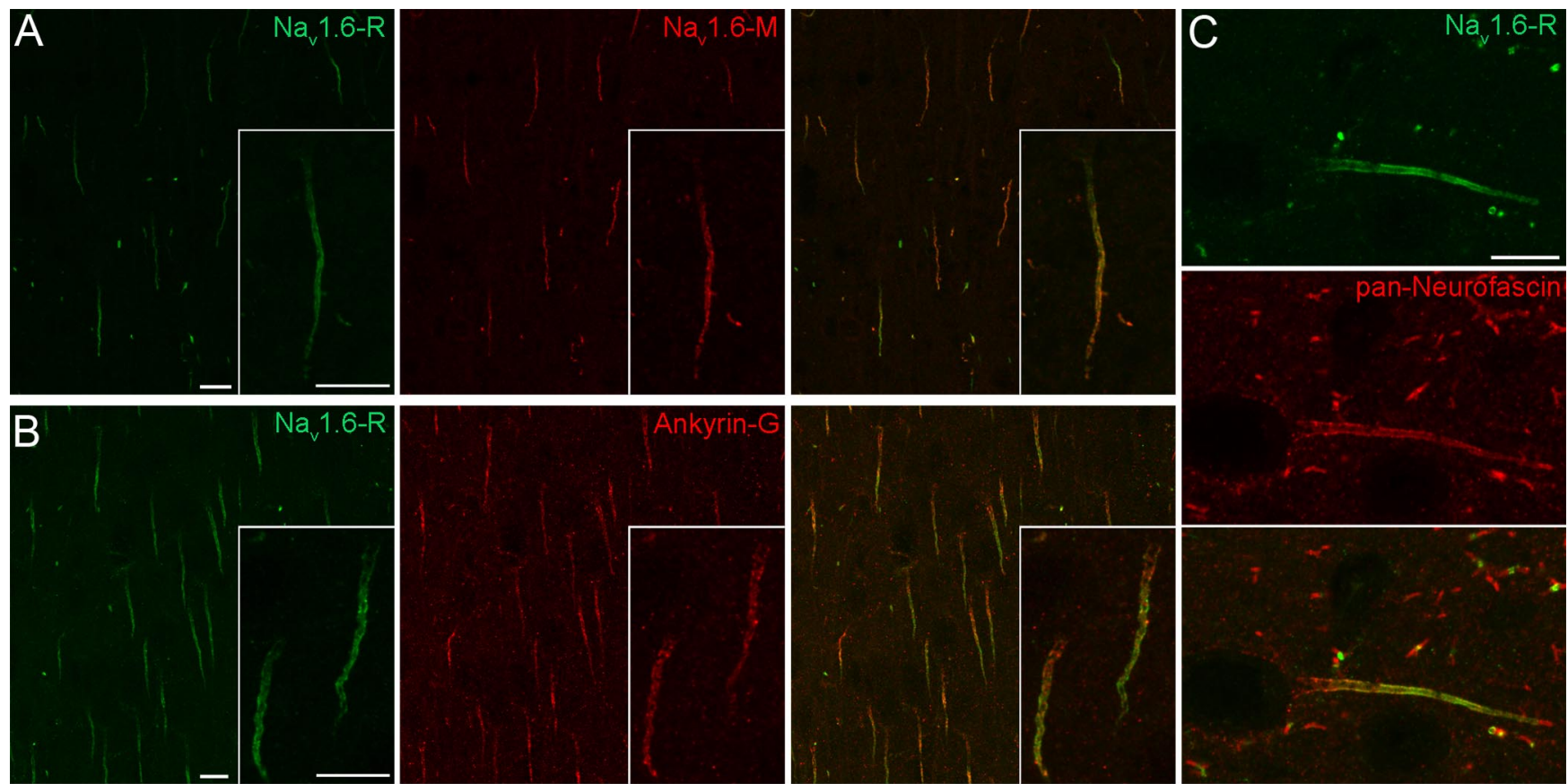

Figure 2. Localization of the Nav1.6 subunit in AISs in layer 2/3 of the neocortex. A, The identical immunolabeling of AISs and nodes of Ranvier with a rabbit (Nav1.6-R) and a mouse (Nav1.6-M) anti-Nav1.6 antibody, raised against different, nonoverlapping epitopes, demonstrates the specificity of the immunolabeling. $\boldsymbol{B}$, $C$, Double immunofluorescent reactions reveal the colocalization of the Nav1.6 subunit with AIS markers Ankyrin- $G(\boldsymbol{B})$ and Neurofascin $(\boldsymbol{C})$. Note the proximo-distal gradient of the Nav1.6 subunit labeling in contrast to the even distribution of Ankyrin- $G(\boldsymbol{B}$, inset) and Neurofascin (C) along the AISs. Scale bars, $10 \mu \mathrm{m}$.

iments with known AIS markers such as Ankyrin-G (Fig. 2B), Neurofascin (Fig. 2C) and the Nav1.6 subunit verified that the intensely labeled processes were indeed AISs. In subsequent experiments, Nav1.6 subunit immunoreactions were used to identify AISs.

\section{Nav and Kv subunits in the AIS of layer 5 and CA3 pyramidal cells}

In pyramidal cells, AP is primarily generated in the AIS due to the low threshold set by the high density of Nav channels (Kole et al., 2008). In neocortical layer 5 PCs and hippocampal CA3 PCs, the exact site of the AP initiation has been recently localized to the distal segment of the AIS by electrophysiological and imaging experiments (Palmer and Stuart, 2006; Meeks and Mennerick, 2007; Shu et al., 2007). To see if it is accompanied by a predominant expression of certain Nav subunits in the distal AIS, we first checked the distribution of the Nav1.6 and Nav1.1 subunits in the AIS of these cells. The AIS of PCs emerges from the basal pole of the cell body and has a characteristic arrowhead appearance. It originates from a relatively wide axon hillock and continuously narrows toward the end of the AIS, where the axon often becomes myelinated. Confocal images of layer 5 PCs revealed a very intense immunosignal for the Nav1.6 subunit that appeared already at the proximal AIS, often emerged directly from the cell body, and showed a rather uniform distribution along the proximodistal axis of the AIS (Fig. 3C,F), without any preferential accumulation in the distal segment. The tube like appearance of the AIS was likely due to the association of the immunosignal with the plasma membrane. The Nav1.1 subunit was not found to be accumulated in the distal segment of the AIS either, as no immunosignal could be detected for the Nav1.1 subunit in PCs at all, only in interneurons (INs) (see Fig. 5I) (see below). Similar distribution for the Nav1.6 subunit was found in CA3 PCs (supplemental Fig. 3, available at www.jneurosci.org as supplemental material). These results suggest that other factors than the distribution of Nav channels within the AIS focus the AP generation to the distal location in layer 5 and CA3 PCs. A possible candidate could be a reduced density of $\mathrm{Kv}$ channels in the distal AIS. Thus, we turned our attention to Kv1 channels widely expressed in axons by examining the subcellular distribution of Kv1.1 and Kv1.2 subunits in layer 5 and CA3 PCs. Low-magnification images of the neocortex revealed that virtually all Nav1.6 subunit immunopositive AISs were immunolabeled for the Kv1.1 (Fig. $3 A$ ) and Kv1.2 (Fig. $3 D$ ) subunits, suggesting their expression in both glutamatergic PCs and GABAergic INs. Immunoreactions for the Kv1.1 and Kv1.2 subunits showed a very similar labeling pattern in PCs; they strongly outlined the AISs, but neither of them could be detected in cell bodies or dendritic shafts. The immunolabeling for both the Kv1.1 (Fig. 3C) and Kv1.2 (Fig. 3F) subunits emerged at a position distal to that of the Nav1.6 subunit and uniformly outlined the rest of the AIS. A similar distribution pattern was found in CA3 PCs (supplemental Fig. 3, available at www.jneurosci.org as supplemental material). These results suggest the lack of relationship between the distribution of Kv1.1 and Kv1.2 subunits and the distal site of AP initiation. However, these results are in agreement with a recent study demonstrating that the shape of AP in layer 5 PCs is controlled by potassium currents mediated by Kv1 subunits in a distance dependent manner in the AIS (Kole et al., 2007).

\section{Differential distribution of Nav and $\mathrm{Kv}$ subunits in the AIS of} layer $2 / 3$ and CA1 pyramidal cells

Neocortical and hippocampal PCs are not completely uniform (Klausberger and Somogyi, 2008); they are heterogeneous with respect to their morphology, molecular content and synaptic target areas. We asked whether the above observed labeling pattern for the Nav1.6, Kv1.1, and Kv1.2 subunits and the lack of Nav1.1 subunit in layer 5 and CA3 PCs is a universal feature of all PCs. 

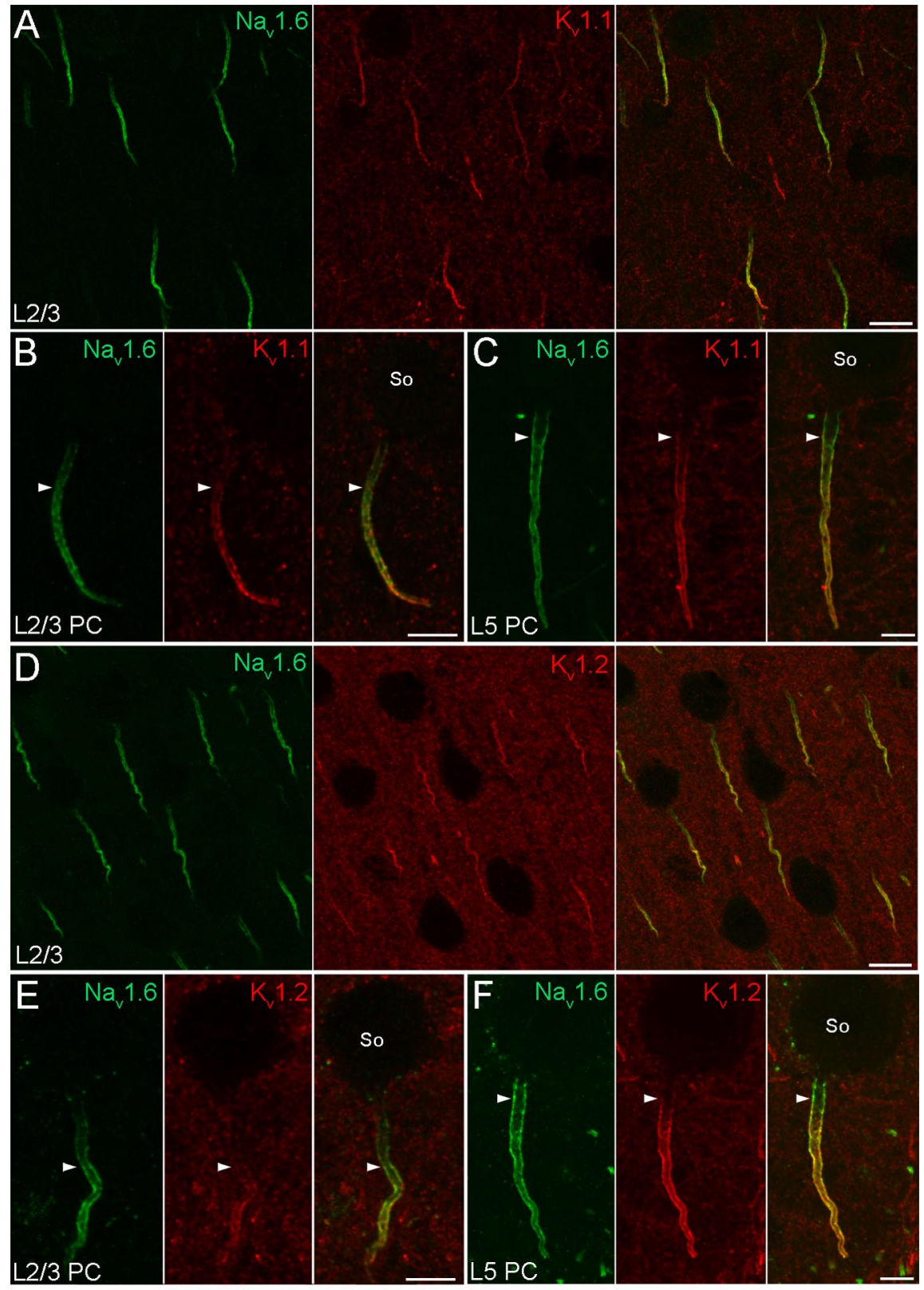

Figure 3. Distribution of the Nav1.6, Kv1.1, and Kv1.2 subunits in the AlS of neocortical PCs. A, B, Double immunofluorescent reactions demonstrate the colocalization of Nav1.6 and Kv1.1 immunolabeling in layer 2/3 PC AISs. B, High-magnification images of a layer 2/3 PC reveal a gradual increase of Nav1.6 and Kv1.1 labeling toward the distal part of the AIS. Immunolabeling for the Kv1.1 subunit begins more distally (arrowheads) compared with that of the Nav1.6 subunit. C, High-magnification images of a layer $5 \mathrm{PC}$ demonstrate a more even Nav1.6 subunit immunolabeling; it appears proximally, close to the axon hillock, whereas the Kv1.1 immunolabeling emerges more distally (arrowheads). $\boldsymbol{D}$, A double immunofluorescent reaction shows the colocalization of Nav1.6 and Kv1.2 subunits in layer 2/3 PC AISs. E, High-magnification images of a layer 2/3 PC reveal a gradual increase of Nav1.6 and Kv1.2 labeling along the AIS. Immunolabeling for the Kv1.2 subunit begins more distally (arrowheads) compared with that of the Nav1.6 subunit. $\boldsymbol{F}$, High-magnification images of a layer $5 \mathrm{PC}$ demonstrate a rather uniform distribution of Nav1.6 subunit immunolabeling, whereas the Kv1.2 immunolabeling appears a bit more distally (arrowheads). So, Soma. Scale bars: $A, D, 10 \mu \mathrm{m}$; $B, C, E, F, 5 \mu \mathrm{m}$.

Similar to layer 5 and CA3 PCs, no immunolabeling for the Nav1.1 subunit could be detected in the AISs of layer $2 / 3$ and CA1 PCs and the somata and dendrites of these cells were also immunonegative for the Nav1.6 subunit. However, immunolabeling for the Nav1.6 subunit was markedly different in their AISs; immunolabeling avoided the proximal segment and gradually increased toward the distal part of the AIS (Fig. $3 B, E$ ). How this distribution pattern influences the site of AP generation is yet unknown, as no electrophysiological information from layer $2 / 3$ or CAl PCs is currently available.

In the AISs of layer $2 / 3$ (Fig. $3 B, E$ ) and CA1 (Fig. $4 B, D$ ) PCs, the immunosignal for both the Kv1.1 (Fig. 3B) and Kv1.2 (Fig. 3E) subunits appeared more distal to that of the Nav1.6 subunit and gradually increased toward the distal part. The identical labeling pattern of Kv1.1 and Kv1.2 subunits suggests that they form heteromeric channels in the AIS of PCs. In line with the lower mRNA expression in CA1 PCs compared with other PCs, the immunolabeling for the Kv1.1 and Kv1.2 subunits was also weaker in CA1 PCs. The identical labeling pattern for Kv1.1 and Kv1.2 subunits however was not ubiquitous in the hippocampus. When examined at low magnifications, immunoreactions for the Kv1.1 and Kv1.2 subunits showed distinct labeling patterns in the neuropil. An intense Kv1.1 subunit labeling was found in the neuropil of strata oriens and radiatum of the CA1 (Fig. $4 A$ ) and CA3 regions (supplemental Fig. $3 A$, available at www.jneurosci.org as supplemental material), corresponding to juxtaparanodal axons and most likely to presynaptic terminals and/or preterminal axons. Mossy fibers in CA3 stratum lucidum were also intensely Kv1.1 subunit immunopositive (supplemental Fig. 3A, available at www. jneurosci.org as supplemental material). For the Kv1.2 subunit however, despite the intense labeling in the juxtaparanodal axons, only a modest immunoreactivity could be seen in the neuropil of the strata oriens and radiatum of the CA1 (Fig. 4C) and $\mathrm{CA} 3$ regions (supplemental Fig. $3 C$, available at www.jneurosci.org as supplemental material) and the mossy fibers were also immunonegative.

\section{Cortical interneuron AISs contain}

distinct Nav and Kv subunits compared with pyramidal cells

In addition to the arrowhead-like, descending AIS of PCs in the neocortex and hippocampus, we often observed Nav1.6 subunit immunopositive AISs of different shapes and orientations in our reactions. A population of these AISs was thinner and shorter than those of PCs with a rather uniform diameter along the whole length (Fig. 5). They often emerged from the apical pole of round or elongated cell bodies (Fig. 5). Previous anatomical studies revealed that axons of neocortical GABAergic INs can emerge from the soma at various positions, often arising from the apical pole and running toward the pia before branching to axon collaterals (Tamás et al., 1998), suggesting that these Nav1.6 subunit immunopositive AISs belong to GABAergic INs. Double immunofluorescent reactions revealed the colocalization of both Kv1.1 (Fig. 
$5 A$ ) and Kv1.2 (Fig. 5B) subunits with the Nav1.6 subunit in putative IN AISs. Double-labeling experiments revealed that the Kv1.1 and Kv1.2 subunit immunoreactive AISs indeed emerged from INs, more specifically from their PV immunopositive subpopulation (Fig. 5C,D). We also noticed that the immunosignal for both of these Kv subunits was more intense in IN AISs compared with that of PCs. Within the AISs of GABAergic INs, the Nav1.6 immunolabeling emerged proximal to the axon hillock and intensely outlined the AIS, but often showed a reduced intensity at the distal tip. Immunosignal for the Kv1.1 and Kv1.2 subunits appeared slightly distal compared with the Nav1.6 subunit and uniformly labeled the AIS along the whole length. In a subpopulation of INs, in contrast to the Nav1.6 subunit, the Kv1.1 (Fig. 5E) and Kv1.2 (Fig. 5F) subunit labeling was not restricted to the AIS, but extended into the ascending axon. Some of these axons were also PV immunopositive (Fig. 5G,H).

Analysis of the Nav1.1 subunit immunoreaction revealed that a population of Nav1.6 subunit immunopositive AISs leaving the apical pole of cell bodies was also immunopositive for the Nav1.1 subunit (Fig. 5I) and emerged from PV+ INs (Fig. $5 K$ ). Interestingly, the Nav1.1 subunit immunolabeling was restricted to the proximal part of the AISs (Fig. 5J). A similar result was obtained in the hippocampus. Antibodies raised against the Nav1.1, Nav1.6, Kv1.1, and Kv1.2 subunits labeled the AIS of PV + INs in the CA1 and CA3 regions, with almost identical distributions and intensities to those observed in neocortical INs.

\section{Unique distribution of Nav and $\mathrm{Kv}$} subunits in main olfactory bulb neurons When immunoreactions for the Nav1.6, Kv1.1, and Kv1.2 subunits were analyzed in the MOB at low magnifications, immunolabeling was found in all layers with subunit-specific labeling patterns. Intense labeling for the Nav1.6 subunit was observed in AISs and nodes of Ranvier in the external plexiform layer (EPL), mitral cell layer (MCL), and granule cell layer (GCL) (Fig. 6A, F). For the Kv1.1 subunit, strong immunolabeling was seen in the GCL (Fig. $6 \mathrm{~A}$, middle). Double-labeling experiments revealed that most of the Nav1.6 subunit immunopositive processes were immunonegative for the Kv1.1 subunit in the EPL and MCL (Fig. 6A). For the Kv1.2 subunit, an intense labeling was observed in the GCL, but the strongest labeling was seen in Nav1.6 immunoreactive AISs in the EPL, MCL, and GCL (Fig. 6 F). To gain insight into the cellular and subcellular distribution of the Nav1.6, Kv1.1, and Kv1.2 subunits, we analyzed the immunoreactions in different
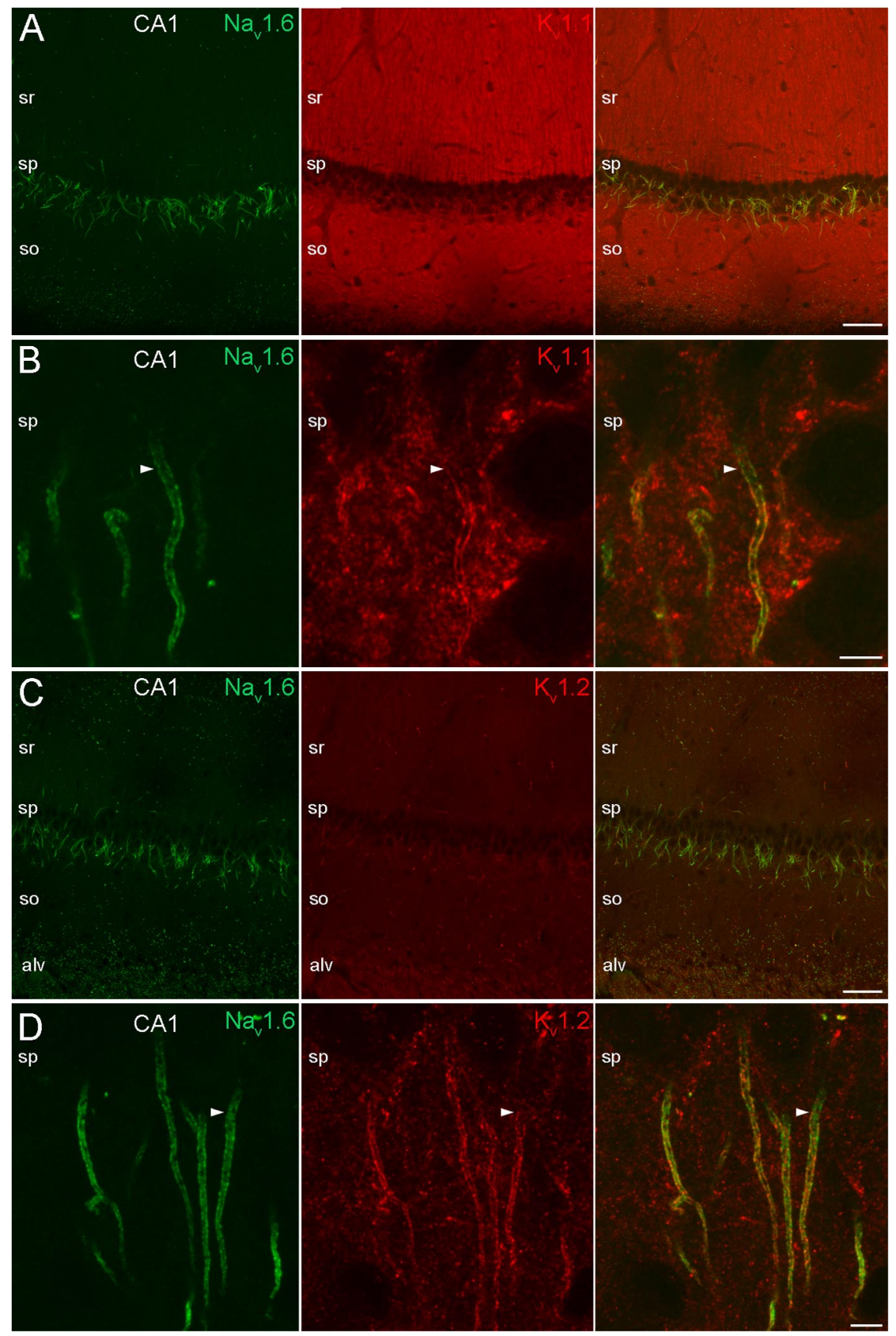

Figure 4. Localization of the Nav1.6, Kv1.1, and Kv1.2 subunits in the AlSs of hippocampal CA1 PCS. A, Low-magnification images of the CA1 area show double immunofluorescent reactions for the Nav1.6 and Kv1.1 subunits. The Nav1.6 subunit immunolabeling is restricted to AISs and nodes of Ranvier, whereas an intense neuropil labeling is observed with the Kv1.1 antibody in strata oriens (so) and radiatum (sr). $\boldsymbol{B}$, High-magnification images of stratum pyramidale (sp) reveal the colocalization of Nav1.6 and Kv1.1 subunits in the plasma membrane of PC AISs. Similar to neocortical PCs, the Nav1.6 subunit immunolabeling begins more proximal to that of the Kv1.1 subunit (arrowheads). C, A double immunofluorescent reaction for the Nav1.6 and Kv1.2 subunits is shown at a low magnification. D, High-magnification images from the sp reveal the colocalization of Nav1.6 and Kv1.2 subunits in PC AISs. Similar to neocortical PCs, the Nav1.6 labeling emerges proximal to that of the Kv1.2 subunit (arrowheads). alv, Alveus. Scale bars: $A, C, 50 \mu \mathrm{m} ; \boldsymbol{B}, \boldsymbol{D}, 5 \mu \mathrm{m}$.

cell types at high magnifications. In mitral and tufted cells $(\mathrm{M} / \mathrm{T})$ (Fig. $6 B, C$ ), an intense and uniform distribution of the Nav1.6 subunit immunolabeling was observed along the whole length of the AISs; however, these cells were immunonegative for the Kv1.1 (Fig. $6 B, C$ ) but immunopositive for the Kv1.2 subunit (Fig. $6 G, H)$. In contrast to cortical PCs, the distribution of the Kv1.2 subunit immunosignal along the AIS of M/T cells was identical to the Nav1.6 subunit labeling. No immunoreactivity was detected 


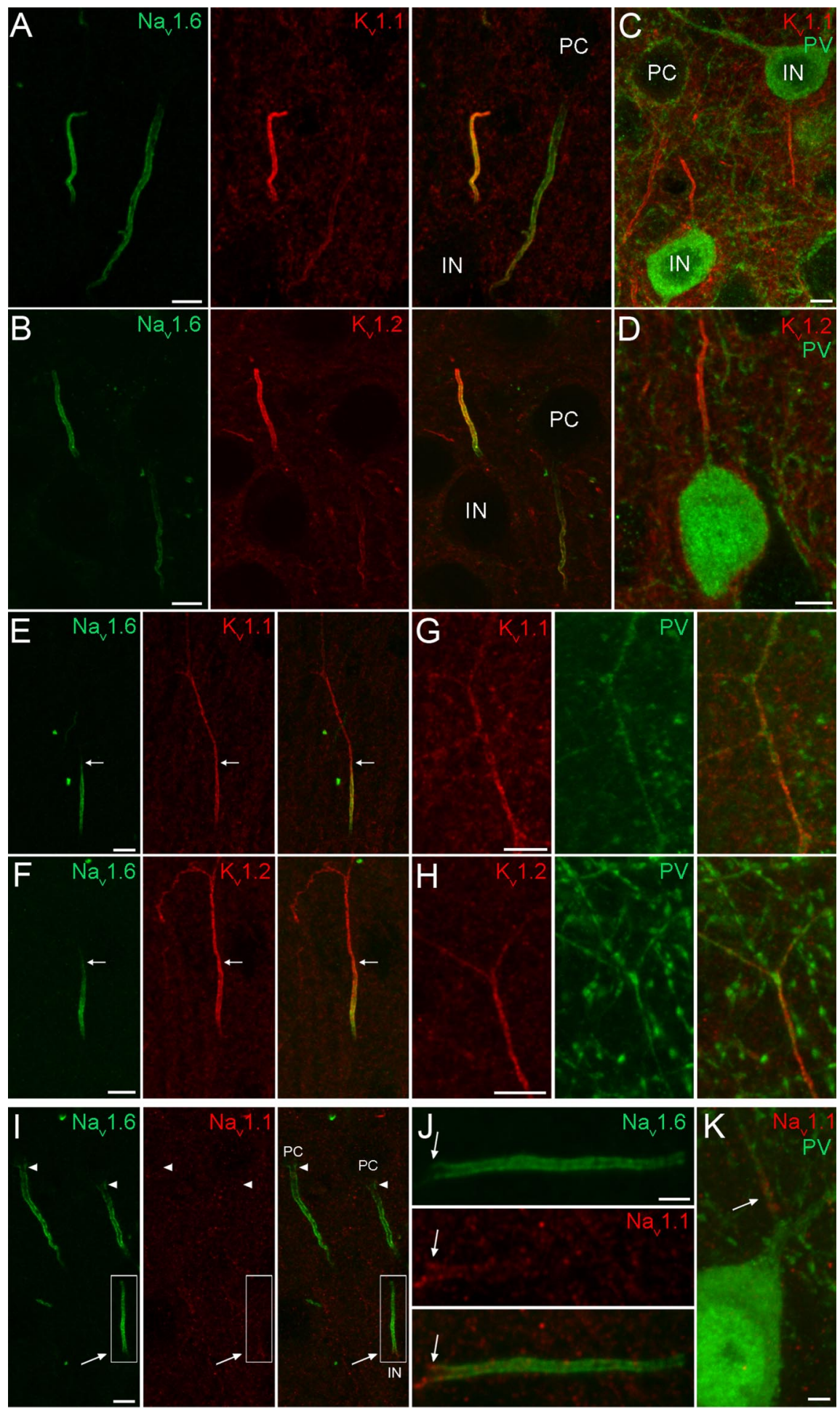

Figure 5. Localization of the Nav1.1, Nav1.6, Kv1.1, and Kv1.2 subunits in the AIS of neocortical INs. $\boldsymbol{A}, \boldsymbol{B}$, Double immunofluorescent reactions showing the colocalization of the Nav1.6 subunit with either Kv1.1 (A) or Kv1.2 (B) subunits in neocortical IN AISs. The AISs of GABAergic INs are more intensely labeled compared with the neighboring PC AIS. C, D, Strongly Kv1.1 (C) and Kv1.2 (D) immunoreactive AISs emerge from PV immunopositive INs. $\boldsymbol{E}, \boldsymbol{F}$, In a subpopulation of INs, in contrast to the Nav1.6 subunit labeling, the Kv1.1 (E) and Kv1.2 (F) labeling is not restricted to the AIS, but extends into the ascending axon. Arrows demarcate the border of the AIS and more distal axon. $\mathbf{G}, \boldsymbol{H}$, Some Kv1.1 (G) and Kv1.2 (H) subunit immunoreactive axons are also immunopositive for PV. I, Double immunofluorescent labeling reveals the absence of Nav1.1 subunit immunoreactivity in PC AISs (arrowheads) and its presence in an IN AIS (arrow) emerging from the apical pole of the IN soma. J, A higher-magnification view of the boxed area in / shows that the Nav1.1 subunit immunolabeling is confined to the proximal part (arrow) of the AIS. $\boldsymbol{K}$, Nav1.1 subunit immunolabeling is present in the proximal part of an axon emerging from a PV immunopositive cell. Scale bars: $\boldsymbol{A}-\boldsymbol{I}, 5$ $\mu \mathrm{m} ; \boldsymbol{J}, \boldsymbol{K}, 2 \mu \mathrm{m}$. for the Nav1.6, Kv1.1, and Kv1.2 subunits in the cell body and apical dendrites of $\mathrm{M} / \mathrm{T}$ cells. Mitral and tufted cells form the major excitatory output of the MOB, whereas local interneurons, such as the short-axon cells (SACs) in the EPL and the deep short-axon cells in the GCL, exert local inhibitory control over GABAergic granule and periglomerular cells. Most periglomerular and all granule cells are axonless, and therefore the distribution of $\mathrm{Kv}$ and Nav channels in their AIS cannot be analyzed. However, we did analyze the immunoreactions in $\mathrm{GABA}_{\mathrm{A}}$ receptor $\left(\mathrm{GABA}_{\mathrm{A}} \mathrm{R}\right) \alpha 1$ subunit immunopositive deep SACs in the GCL and found that both the K1.1 (Fig. 6D,E) and Kv1.2 (Fig. 6I,J) subunits colocalize with the Nav1.6 subunit in the whole length of the AIS. A similar expression pattern was found for the Nav1.6, Kv1.1, and Kv1.2 subunits in short-axon cells of the EPL (data not shown). These results suggest the ubiquitous expression of the Kv1.2 subunit in the AIS of different cell types in the MOB, and the selective expression of the Kv1.1 subunit in the AIS of SACs.

In the next experiments, we analyzed the expression of the Nav1.1 subunit in the MOB. Double immunofluorescent reactions with Nav1.1 and Nav1.6 subunit antibodies demonstrated the absence of immunosignal for the Nav1.1 subunit in the AIS of $\mathrm{M} / \mathrm{T}$ cells (Fig. $6 \mathrm{~K}$ ). However, Nav1.1 subunit immunoreactivity was observed in the EPL along the whole length of thin, horizontally oriented AISs in full overlap with the Nav1.6 subunit (Fig. $6 K, L)$. These cells were identified as SACs in double-labeling experiments. Figure $6 \mathrm{M}$ shows the Nav1.1 subunit immunolabeling outlining an axon emerging from the dendrite of a PV immunopositive SAC in the EPL. In deep SACs in the GCL, we also observed immunosignal for the Nav1.1 subunit. However, in these AISs the Nav1.1 subunit labeling was restricted to the proximal part, similar to the labeling pattern observed in cortical and hippocampal INs. These results demonstrate a cell type-specific subcompartmental distribution of the Nav1.1 subunits in distinct GABAergic INs of the MOB.

\section{Cerebellar Purkinje cells and}

GABAergic interneurons differentially express Nav and Kv subunits

At low magnifications, the strongest immunolabeling in the cerebellar cortex for both the Kv1.1 (Fig. 7A) and Kv1.2 (Fig. $7 B$ ) subunits was seen in the dense axonal plexus of basket cells that surrounds Purkinje cell AISs (called pinceau) as reported 


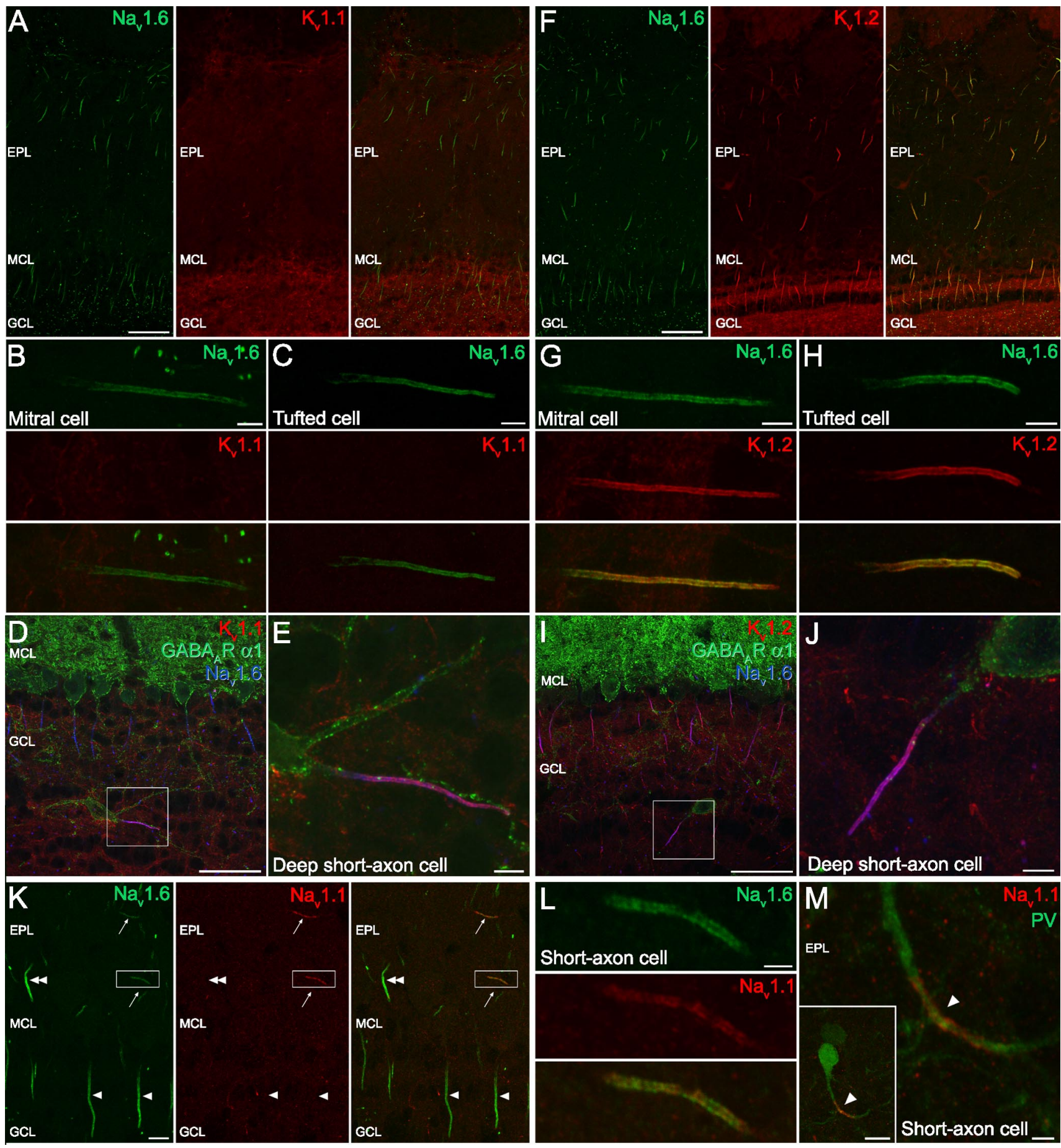

Figure 6. Distribution of the Nav1.1, Nav1.6, Kv1.1, and Kv1.2 subunits in the MOB. A-E, Colocalization of Nav1.6 and Kv.1.1 subunits. A, Double immunofluorescent reaction showing the distribution of Nav1.6 and Kv1.1 subunits in the MOB. B, C, High-magnification images of a mitral ( $\boldsymbol{B}$ ) and a tufted ( $\boldsymbol{C}$ ) cell AlS immunopositive for Nav1.6, but immunonegative for Kv1.1 subunit. $\boldsymbol{D}$, Nav1.6 and Kv1.1 subunits are coexpressed (purple) in an AIS emerging from a GABA $A_{A} R \alpha 1$ immunopositive deep SAC. $\boldsymbol{E}$, A higher-magnification view of the boxed area shown in $\boldsymbol{D}$. $\boldsymbol{F}$, Double immunofluorescent reaction showing the distribution of the Nav1.6 and Kv1.2 subunits in the MOB. G, $\boldsymbol{H}$, High-magnification images of a mitral $(\boldsymbol{G})$ and a tufted $(\boldsymbol{H})$ cell AIS immunopositive for both the Nav1.6 and the Kv1.2 subunits. $I, J$, Nav1.6 and Kv1.2 subunits are colocalized (purple; at higher magnification in $\boldsymbol{J}$ ) in the plasma membrane of an AIS emerging from a GABA $R$ R $\alpha 1$ immunopositive deep SAC. $\boldsymbol{K}$, A double immunofluorescent reaction reveals the presence of Nav1.1 subunit immunolabeling in SAC AISs in the EPL (arrows), which are also immunopositive for the Nav1.6 subunit. The AISs of tufted (double arrowhead) and mitral (arrowheads) cells do not contain a detectable amount of the Nav1.1 subunit. $L$, A higher-magnification view of the boxed area in $\boldsymbol{K}$ shows the overlap of Nav1.6 and Nav1.1 subunit labeling along the full length of the AIS. $M$, Nav1.1 subunit immunolabeling outlines the proximal part of an axon (arrowhead) emerging from the dendrite of a PV immunopositive SAC in the EPL. Scale bars: $A, D, F, I, 50 \mu \mathrm{m} ; \boldsymbol{B}, \boldsymbol{C}, \boldsymbol{E}, \boldsymbol{G}, \boldsymbol{H}, \boldsymbol{J}, 5 \mu \mathrm{m} ; \boldsymbol{K}, \boldsymbol{M}$ (inset), $10 \mu \mathrm{m} ; \boldsymbol{L}, \boldsymbol{M}, 2 \mu \mathrm{m}$.

previously (Rhodes et al., 1997). At high magnifications, double immunofluorescent reactions demonstrated that the Nav1.6 subunit immunolabeling is evenly distributed along Purkinje cell AIS plasma membranes without detectable immunosignal for the
Kv1.1 (Fig. 7C) and Kv1.2 (Fig. 7D) subunits. Interneurons in the molecular layer coexpressed the Nav1.6 with the Kv1.1 (Fig. 7E) and Kv1.2 (Fi. $7 F$ ) subunits in their horizontally oriented AISs. Similar to neocortical INs, there was little or no detectable Kv1.1 


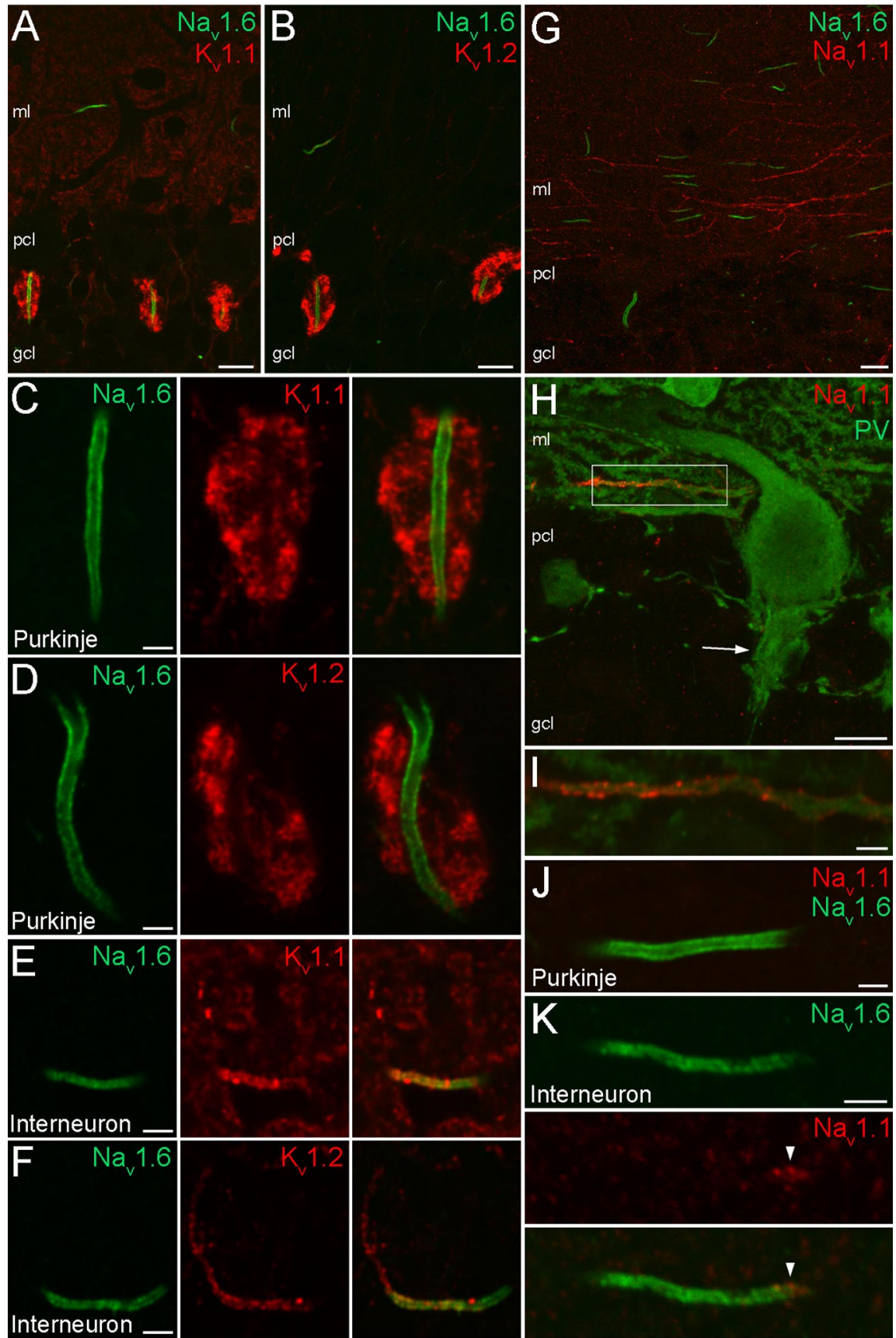

Figure 7. Distribution of Nav1.1, Nav1.6, Kv1.1, and Kv1.2 subunits in the cerebellum. $\boldsymbol{A}, \boldsymbol{B}$, Double immunofluorescent reactions demonstrate the colocalization of the Nav1.6 subunit with either the Kv1.1 (A) or the Kv1.2 (B) subunits in the cerebellar cortex. $\boldsymbol{C}, \boldsymbol{D}$, In Purkinje cell AISs, the Nav1.6 subunit immunolabeling is evenly distributed, but no immunosignal for the Kv1.1 ( $\boldsymbol{C}$ ) and Kv1.2 (D) subunits is detected; this is detected only in the surrounding axonal plexus (pinceau) of basket cells. $\boldsymbol{E}, \boldsymbol{F}$, Interneurons in the molecular layer coexpress the Nav1.6 with the Kv1.1 (E) and Kv1.2 (F) subunits in their AISs. Similar to neocortical INs, there was no detectable Kv1.1 and Kv1.2 subunit immunosignal in the proximal part of the AIS. G, Double immunofluorescent reaction of Nav1.6 and Nav1.1 subunits in the cerebellar cortex shows intense Nav1.1 subunit labeling in Nav1.6 subunit immunonegative, putative basket cell axons running parallel with the Purkinje cell layer ( $\mathrm{pcl}$ ). $\boldsymbol{H}, \mathrm{A}$ double immunofluorescent reaction shows a PV and Nav1.1 subunit immunopositive axon. Note that the neighboring PV immunopositive Purkinje cell processes, as well as the pinceau (arrow), are all immunonegative for the Nav1.1 subunit. I, A higher-magnification view of the boxed area shown in $\boldsymbol{H}$.J, A Nav1.6 subunit immunopositive, but Nav1.1 subunit immunonegative Purkinje cell AIS is shown. $\boldsymbol{K}$, Immunoreactive Nav1.1 and Nav1.6 subunits are segregated in the AIS of a molecular layer IN. ml, Molecular layer. Scale bars: $\boldsymbol{A}, \boldsymbol{B}, \mathbf{G}, \boldsymbol{H}, 10 \mu \mathrm{m} ; \boldsymbol{C}-\boldsymbol{F}, \boldsymbol{I}-\boldsymbol{K}, 2 \mu \mathrm{m}$.

and Kv1.2 subunit immunosignal in the proximal part of the AISs, but the intense immunolabeling extended to the axon proper. Antibodies raised against the Nav1.1 subunit strongly labeled putative basket cell axons in the molecular layer (Fig. 7G).
Indeed, double immunofluorescent reactions demonstrated the presence of PV in these large diameter horizontally running axons (Fig. $7 \mathrm{H}, \mathrm{I}$ ). However, another part of the basket cell axon, the pinceau, was completely immunonegative for the Nav1.1 subunit (Fig. 7H, arrow). Further analysis of molecular layer INs revealed that their AISs were Nav1.1 subunit immunopositive. Double-labeling experiments demonstrated a polarized, nonoverlapping distribution of the Nav1.6 and Nav1.1 subunits along the AIS (Fig. $7 K$ ). The Nav1.1 subunit immunolabeling was restricted to a short, proximal segment of the AIS whereas immunolabeling for Nav1.6 subunit was evenly distributed in the rest of AIS. The PV immunopositive Purkinje cell processes were immunonegative for the Nav1.1 subunit (Fig. $7 \mathrm{H}, J$ ). In summary, Purkinje cells comprise the only studied cell type without a detectable expression of the Kv1.1 and Kv1.2 subunits, and the examined Nav and Kv channel subunits showed the most complex subcellular distribution patterns in the axons of molecular layer INs.

A summary and a schematic illustration of our results are presented in Figure 8. Neocortical and hippocampal PCs do not express the Nav1.1 subunit in their AISs at a detectable level. In layer $2 / 3$ and CA1 PCs the density of the Nav1.6 subunit gradually increases toward the distal part of the AIS. The Kv1.1 and Kv1.2 subunits are present more distally and show a similar proximo-distal gradient along the AIS. In layer 5 and CA3 PCs, a high density of the Nav1.6 subunit is already seen at the axon hillock and is uniformly present along the whole AIS, whereas the Kv1.1 and Kv1.2 subunits appear at a detectable density more distally. In $\mathrm{M} / \mathrm{T}$ cells in the MOB, only Nav1.6 and Kv1.2 subunits are detected, and they colocalize along the entire length of the AIS. The AIS of cerebellar Purkinje cells is immunoreactive only for the Nav1.6 subunit, which is evenly distributed within the AIS. GABAergic INs in the neocortex, hippocampus, cerebellum, and MOB contain all four subunits at high densities in their AISs. These INs fall into two categories based on the distribution of the Nav1.1 subunit. In neocortical, hippocampal, cerebellar INs and deep SACs, the Nav1.1 subunit is restricted to the proximal part of the AIS, whereas in SACs of the EPL, the Nav1.1 subunit is uniformly distributed along the entire length of the AIS.

\section{Discussion}

The main finding of our present work is the demonstration of a large heterogeneity of AISs with regard to the subunit composi- 


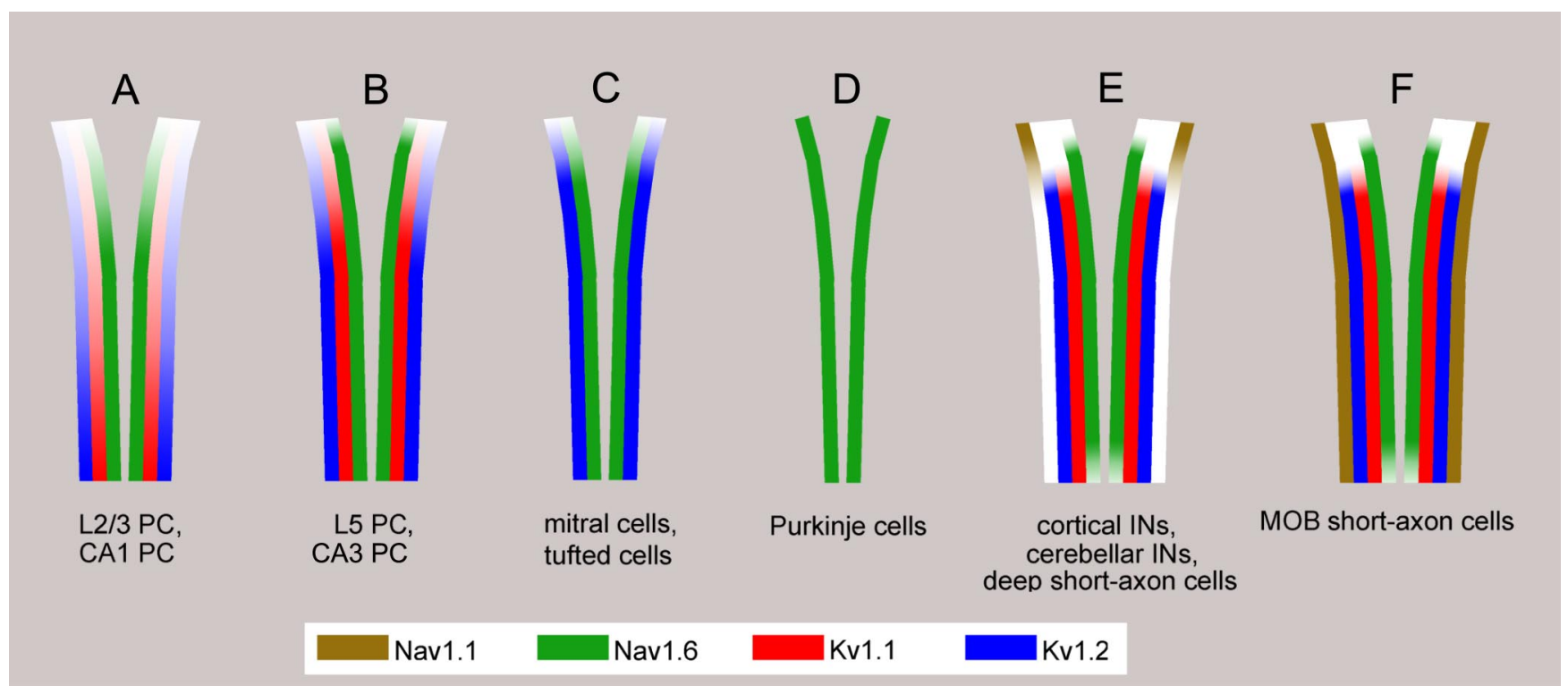

Figure 8. Molecular composition of the AISs of distinct types of nerve cells. $\boldsymbol{A}, \boldsymbol{B}$, Neocortical and hippocampal PCs do not express the Nav1.1 subunit in their AISs at a detectable level. $\boldsymbol{A}$, In layer 2/3 and CA1 PCs, the density of Nav1.6 subunit increases toward the distal part of the AIS. The Kv1.1 and Kv1.2 subunits are localized more distally, and their density also gradually increases toward the end of the AIS. B, In layer 5 and CA3 PCs, a high density of the Nav1.6 subunit is already present at the axon hillock and is uniformly distributed along the AIS. The Kv1.1 and Kv1.2 subunits appear slightly more distally and both have a rather uniform distribution at high densities along the AIS. C, In M/T cells in the MOB, only Nav1.6 and Kv1.2 subunits are detected and they colocalize along the whole length of the AIS. D, The AIS of cerebellar Purkinje cells is only immunoreactive for the Nav1.6 subunit. $E$, $F$, GABAergic INs in the neocortex, hippocampus, cerebellum, and MOB express all four subunits at high densities in their AISs. E, In cortical INs, cerebellar INs, and MOB deep SACs, the Nav1.1 subunit was restricted to the proximal AIS, whereas EPL short-axon cells of the MOB $(\boldsymbol{F})$ have an even distribution of the Nav1.1 subunit along their AlS.

tion, density and precise subcompartmental distribution of voltage-gated sodium and potassium channels. This heterogeneity could play a key role in the cell type-dependent variability in the site of AP initiation and the firing properties of distinct nerve cells.

\section{Cell type-specific expression and polarization of Nav1.1 and Nav1.6 subunits in the AIS}

Ten Nav $\alpha$ subunit genes have been identified in mammals, four of which (Nav1.1. Nav1.2, Nav1.3 and Nav1.6) are expressed predominantly in the brain. During the first 2 weeks of postnatal development, the Nav1.2 subunit is strongly expressed in retinal ganglion cell AISs then it is replaced by the Nav1.6 subunit (Boiko et al., 2001, 2003; Van Wart and Matthews, 2006a). This change in expression coincides with the appearance of repetitive firing modes in these cells (Van Wart and Matthews, 2006b). We showed that in adult rats the highest density of the Nav1.6 subunit is present in the AISs of all major neuron types of the neocortex, hippocampus, cerebellum and MOB, suggesting that the primary site for AP initiation is the AIS in most nerve cells. Why is the Nav1.6 preferred over the other $\mathrm{Nav} \alpha$-subunits in the AISs? The activation threshold of the Nav1.6 subunit is shifted to a more hyperpolarized potential (by $\sim 15-25 \mathrm{mV}$ ) compared with that of Nav1.2 (Rush et al., 2005) and Nav1.1 subunits (Spampanato et al., 2001), ensuring lower threshold for AP generation. The Nav1.2 (Rush et al., 2005) and Nav1.1 subunits (Spampanato et al., 2001) show a robust use-dependent inactivation at frequencies $>20 \mathrm{~Hz}$ (Rush et al., 2005), which would prevent highfrequency firing of nerve cells. Indeed, cerebellar Purkinje cells from mice lacking the Nav1.6 subunit (Raman et al., 1997) showed impaired ability to fire bursts of APs at high frequencies. In Purkinje cells, we could only detect the Nav1.6 subunit at high densities along the whole length of the AIS. Although mRNAs for both Nav1.1 and Nav1.6 subunits are expressed in Purkinje cells
(Vega-Saenz de Miera et al., 1997), the Nav1.1 subunit seems to appear in the AIS only when it compensates for the loss of the Nav1.6 subunit in Nav1.6 deficient mice (Van Wart and Matthews, 2006b)

In the AIS of neocortical and hippocampal PCs, we could detect only the Nav1.6 as Nav subunit, but with slightly different subcompartmental distributions. The importance of the gradual versus even distributions between layer $2 / 3$ and layer 5 PCs is yet unclear; it may underlie some differences in AP initiation. Nevertheless, the high distal density of the Nav1.6 subunit is likely to facilitate the generation of AP in the distal part of the AIS (Palmer and Stuart, 2006; Shu et al., 2007; Kole et al., 2008) and in the proximal part of layer 5 PCs it may help to overcome the large electrical load of soma and dendrites and facilitate the backpropagation of APs to the soma.

In accordance with a previous study (Ogiwara et al., 2007), we have demonstrated the predominant expression of Nav1.1 subunit in PV immunopositive GABAergic INs in all studied brain areas. Mutations or lack of this subunit are associated with severe childhood epilepsy, and in mice it leads to premature death (Claes et al., 2003; Yu et al., 2006). Whereas the Nav1.6 subunit occupies a large part of the AIS, the Nav1.1 subunit is restricted to a small proximal segment of the AIS of cortical and cerebellar INs. Similar striking spatial segregation of these subunits were found in retinal ganglion cells (Van Wart et al., 2007), which are able to fire at high frequencies. As the high frequency firing of fastspiking cortical INs is impaired in mice deficient for the Nav1.1 subunit, we speculate that the combined activation of Nav1.1 and Nav1.6 subunits may be necessary for reliable high-frequency firing and to reach the high AP threshold set by Kvl channels (see below). However, the impact of uniform Nav1.1 subunit distribution and its complete overlap with the Nav1.6 subunit in MOB SACs is yet unknown.

None of the studied cell types contained Nav1.1 or Nav1.6 
subunits at a detectable level in their somato-dendritic compartments. This lack of labeling is likely to be the consequence of a very low density of these subunits in the somato-dendritic plasma membranes. However, the possibility cannot be excluded that those subunits that are located in the somato-dendritic membranes are masked in a way that even pepsin-treatment cannot retrieve their epitopes, rendering those subcellular compartments immunonegative despite their Nav subunit content. Future studies using either new antigen-retrieval methods or completely novel immunohistochemical techniques such as SDSetched freeze-fracture replica labeling will help us to distinguish between these possibilities.

\section{Cell type-specific segregation of Kv1 and Nav channels}

Voltage-gated potassium channel subunits Kv1.1, Kv1.2, Kv1.3, $\mathrm{Kv} 1.4$ and Kv1.6 comprise the major Kv1 $\alpha$ subunits in the mammalian brain. Here, we have demonstrated that when both Kv1.1 and Kv1.2 subunits are present in the AIS of a cell, they show identical distribution along the AIS (Figs. 3, 4, 5), suggesting that they might share the same anchoring machinery and form heteromeric channels. Several anchoring proteins including Caspr2 (Inda et al., 2006) and PSD-93 (Ogawa et al., 2008) have been implicated in clustering Kv1 channels in the AIS. Heteromeric assembly is also supported by recent experiments showing that homomeric Kv1.1 channels are retained in the endoplasmic reticulum (Manganas and Trimmer, 2000). When different Kv1 $\alpha$ subunits coassemble, they can generate a large diversity of channels with different kinetic properties. This heterogeneity is further increased by associated $\beta$ subunits (McIntosh et al., 1997). Recently, the Kv1.4 subunit was also localized to the AIS of cortical cells in P10 rats (Ogawa et al., 2008). The expression of this subunit converted the delayed rectifier Kv1.1/Kv1.2 channels to fast inactivating, transient A-type channels. It is yet to be determined whether Kv1.4 and other Kv1 subunits are coexpressed in cortical AISs in the adult brain and if the Kv1.4 subunit is expressed what proportion of the $\mathrm{K}$ current is transformed to an A-type current in the AIS. It should be noted, however, that Kv4.2 and Kv4.3 subunits, which also confer A-type pharmacological and kinetic properties to the channels, are not concentrated in AISs of hippocampal, cortical, cerebellar or olfactory bulb neurons (Kollo et al., 2006, 2008).

Our experiments also revealed that in cells where the Kv1.1 and Kv1.2 subunits are coexpressed with the Nav1.6 subunit, their subcellular distributions are correlated. For example, in AISs where the Nav1.6 subunit distribution shows a strong gradient, the Kv1.1/Kv1.2 subunits also increase in density toward the distal part of the AIS (e.g., layer 2/3 PCs) (Fig. 3B,E); conversely, if the gradient is less pronounced for the Nav1.6 subunit, the Kv1.1/Kv1.2 subunits are also distributed rather evenly (layer 5 PCs) (Fig. 3C,F). Such a correlated subcompartmental expression of major Nav and Kv1 subunits in the AISs might be a general rule for every cell type of the CNS, the functional consequences of which is yet unclear.

The AIS of cortical PCs is unique because it receives GABAergic innervation from a specialized type of INs called chandelier or axo-axonic cells (Somogyi et al., 1982; Howard et al., 2005). In most neocortical areas, the majority of chandelier cell axons heavily innervates layer 2/3 PCs, but only sparsely layer 5 PCs (Inda et al., 2008). As the development of GABAergic inhibition can be influenced by the expression of Kvl channels (Howard et al., 2007), we suggest that the development of the gradient distribution of Nav1.6, Kv1.1, and Kv1.2 subunits in layer 2/3 and CA1
PCs might be linked to the developmental appearance of axoaxonic synapses on these AISs.

Compared with PCs, a much higher density of Kv1.1 and Kv1.2 subunit immunoreactivity was found in the AIS of PV containing GABAergic INs. Such a high Kv channel density suggests an increased threshold for AP generation. In agreement with our results, Goldberg et al. (2008) have demonstrated that slow inactivation of Kv1 channels in cortical fast spiking cells shifts the threshold for AP generation. Reaching this increased AP threshold might require the cooperated activation of the AIS Nav1.6 and Nav1.1 subunits in GABAergic INs, a mechanisms that is missing in cortical PCs.

\section{References}

Bean BP (2007) The action potential in mammalian central neurons. Nat Rev Neurosci 8:451-465.

Boiko T, Rasband MN, Levinson SR, Caldwell JH, Mandel G, Trimmer JS, Matthews G (2001) Compact myelin dictates the differential targeting of two sodium channel isoforms in the same axon. Neuron 30:91-104.

Boiko T, Van Wart A, Caldwell JH, Levinson SR, Trimmer JS, Matthews G (2003) Functional specialization of the axon initial segment by isoformspecific sodium channel targeting. J Neurosci 23:2306-2313.

Brew HM, Gittelman JX, Silverstein RS, Hanks TD, Demas VP, Robinson LC, Robbins CA, McKee-Johnson J, Chiu SY, Messing A, Tempel BL (2007) Seizures and reduced life span in mice lacking the potassium channel subunit Kv1.2, but hypoexcitability and enlarged Kv1 currents in auditory neurons. J Neurophysiol 98:1501-1525.

Claes L, Ceulemans B, Audenaert D, Smets K, Löfgren A, Del-Favero J, AlaMello S, Basel-Vanagaite L, Plecko B, Raskin S, Thiry P, Wolf NI, Van Broeckhoven C, De Jonghe P (2003) De novo SCN1A mutations are a major cause of severe myoclonic epilepsy of infancy. Hum Mutat 21:615-621.

Clark BA, Monsivais P, Branco T, London M, Häusser M (2005) The site of action potential initiation in cerebellar Purkinje neurons. Nat Neurosci 8:137-139.

Geiger JR, Jonas P (2000) Dynamic control of presynaptic Ca(2+) inflow by fast-inactivating $\mathrm{K}(+)$ channels in hippocampal mossy fiber boutons. Neuron 28:927-939.

Goldberg EM, Clark BD, Zagha E, Nahmani M, Erisir A, Rudy B (2008) K+ channels at the axon initial segment dampen near-threshold excitability of neocortical fast-spiking GABAergic interneurons. Neuron 58:387-400.

Hedstrom KL, Xu X, Ogawa Y, Frischknecht R, Seidenbecher CI, Shrager P, Rasband MN (2007) Neurofascin assembles a specialized extracellular matrix at the axon initial segment. J Cell Biol 178:875-886.

Howard A, Tamas G, Soltesz I (2005) Lighting the chandelier: new vistas for axo-axonic cells. Trends Neurosci 28:310-316.

Howard MA, Burger RM, Rubel EW (2007) A developmental switch to GABAergic inhibition dependent on increases in Kv1-type K+ currents. J Neurosci 27:2112-2123.

Inda MC, DeFelipe J, Muñoz A (2006) Voltage-gated ion channels in the axon initial segment of human cortical pyramidal cells and their relationship with chandelier cells. Proc Natl Acad Sci U S A 103:2920-2925.

Inda MC, Defelipe J, Munoz A (2008) Morphology and distribution of chandelier cell axon terminals in the mouse cerebral cortex and claustroamygdaloid complex. Cereb Cortex. Advance online publication. Retrieved December 2, 2008. doi:10.1093/cercor/bhn057

Jenkins SM, Bennett V (2001) Ankyrin-G coordinates assembly of the spectrin-based membrane skeleton, voltage-gated sodium channels, and L1 CAMs at Purkinje neuron initial segments. J Cell Biol 155:739-746.

Klausberger T, Somogyi P (2008) Neuronal diversity and temporal dynamics: the unity of hippocampal circuit operations. Science 321:53-57.

Kole MH, Letzkus JJ, Stuart GJ (2007) Axon initial segment Kvl channels control axonal action potential waveform and synaptic efficacy. Neuron 55:633-647.

Kole MH, Ilschner SU, Kampa BM, Williams SR, Ruben PC, Stuart GJ (2008) Action potential generation requires a high sodium channel density in the axon initial segment. Nat Neurosci 11:178-186.

Kollo M, Holderith NB, Nusser Z (2006) Novel subcellular distribution pattern of A-type $\mathrm{K}^{+}$channels on neuronal surface. J Neurosci 26:2684-2691.

Kollo M, Holderith N, Antal M, Nusser Z (2008) Unique clustering of 
A-type potassium channels on different cell types of the main olfactory bulb. Eur J Neurosci 27:1686-1699.

Lorincz A, Nusser Z (2008) Specificity of immunoreactions: the importance of testing specificity in each method. J Neurosci 28:9083-9086.

Lörincz A, Notomi T, Tamás G, Shigemoto R, Nusser Z (2002) Polarized and compartment-dependent distribution of HCN1 in pyramidal cell dendrites. Nat Neurosci 5:1185-1193.

Lörincz A, Rózsa B, Katona G, Vizi ES, Tamás G (2007) Differential distribution of NCX1 contributes to spine-dendrite compartmentalization in CA1 pyramidal cells. Proc Natl Acad Sci U S A 104:1033-1038.

Manganas LN, Trimmer JS (2000) Subunit composition determines Kv1 potassium channel surface expression. J Biol Chem 275:29685-29693.

McIntosh P, Southan AP, Akhtar S, Sidera C, Ushkaryov Y, Dolly JO, Robertson B (1997) Modification of rat brain Kv1.4 channel gating by association with accessory Kvbeta1.1 and beta2.1 subunits. Pflugers Arch 435:43-54.

Meeks JP, Mennerick S (2007) Action potential initiation and propagation in CA3 pyramidal axons. J Neurophysiol 97:3460-3472.

Meisler MH, Plummer NW, Burgess DL, Buchner DA, Sprunger LK (2004) Allelic mutations of the sodium channel SCN8A reveal multiple cellular and physiological functions. Genetica 122:37-45.

Ogawa Y, Horresh I, Trimmer JS, Bredt DS, Peles E, Rasband MN (2008) Postsynaptic density-93 clusters Kv1 channels at axon initial segments independently of Caspr2. J Neurosci 28:5731-5739.

Ogiwara I, Miyamoto H, Morita N, Atapour N, Mazaki E, Inoue I, Takeuchi T, Itohara S, Yanagawa Y, Obata K, Furuichi T, Hensch TK, Yamakawa K (2007) $\mathrm{Na}(\mathrm{v}) 1.1$ localizes to axons of parvalbumin-positive inhibitory interneurons: a circuit basis for epileptic seizures in mice carrying an Scnla gene mutation. J Neurosci 27:5903-5914.

Palmer LM, Stuart GJ (2006) Site of action potential initiation in layer 5 pyramidal neurons. J Neurosci 26:1854-1863.

Planells-Cases R, Caprini M, Zhang J, Rockenstein EM, Rivera RR, Murre C, Masliah E, Montal M (2000) Neuronal death and perinatal lethality in voltage-gated sodium channel alpha(II)-deficient mice. Biophys J 78:2878-2891.

Raman IM, Sprunger LK, Meisler MH, Bean BP (1997) Altered subthreshold sodium currents and disrupted firing patterns in Purkinje neurons of Scn8a mutant mice. Neuron 19:881-891.

Rhodes KJ, Strassle BW, Monaghan MM, Bekele-Arcuri Z, Matos MF, Trimmer JS (1997) Association and colocalization of the Kvbetal and Kvbeta2 beta-subunits with Kv1 alpha-subunits in mammalian brain $\mathrm{K}+$ channel complexes. J Neurosci 17:8246-8258.

Rush AM, Dib-Hajj SD, Waxman SG (2005) Electrophysiological properties of two axonal sodium channels, Nav1.2 and Nav1.6, expressed in mouse spinal sensory neurones. J Physiol 564:803-815.
Schmidt-Hieber C, Jonas P, Bischofberger J (2008) Action potential initiation and propagation in hippocampal mossy fibre axons. J Physiol 586:1849-1857.

Shu Y, Duque A, Yu Y, Haider B, McCormick DA (2007) Properties of action-potential initiation in neocortical pyramidal cells: evidence from whole cell axon recordings. J Neurophysiol 97:746-760.

Smart SL, Lopantsev V, Zhang CL, Robbins CA, Wang H, Chiu SY, Schwartzkroin PA, Messing A, Tempel BL (1998) Deletion of the K(V)1.1 potassium channel causes epilepsy in mice. Neuron 20:809-819.

Somogyi P, Freund TF, Cowey A (1982) The axo-axonic interneuron in the cerebral cortex of the rat, cat and monkey. Neuroscience 7:2577-2607.

Southan AP, Robertson B (2000) Electrophysiological characterization of voltage-gated $\mathrm{K}(+)$ currents in cerebellar basket and purkinje cells: Kv1 and $\mathrm{Kv} 3$ channel subfamilies are present in basket cell nerve terminals. J Neurosci 20:114-122.

Spampanato J, Escayg A, Meisler MH, Goldin AL (2001) Functional effects of two voltage-gated sodium channel mutations that cause generalized epilepsy with febrile seizures plus type 2. J Neurosci 21:7481-7490.

Tamás G, Somogyi P, Buhl EH (1998) Differentially interconnected networks of GABAergic interneurons in the visual cortex of the cat. J Neurosci 18:4255-4270.

Van Wart A, Matthews G (2006a) Expression of sodium channels Nav1.2 and Nav1.6 during postnatal development of the retina. Neurosci Lett 403:315-317.

Van Wart A, Matthews G (2006b) Impaired firing and cell-specific compensation in neurons lacking navl.6 sodium channels. J Neurosci 26:7172-7180.

Van Wart A, Trimmer JS, Matthews G (2007) Polarized distribution of ion channels within microdomains of the axon initial segment. J Comp Neurol 500:339-352.

Vega-Saenz de Miera EC, Rudy B, Sugimori M, Llinás R (1997) Molecular characterization of the sodium channel subunits expressed in mammalian cerebellar Purkinje cells. Proc Natl Acad Sci U S A 94:7059-7064.

Watanabe M, Fukaya M, Sakimura K, Manabe T, Mishina M, Inoue Y (1998) Selective scarcity of NMDA receptor channel subunits in the stratum lucidum (mossy fibre-recipient layer) of the mouse hippocampal CA3 subfield. Eur J Neurosci 10:478-487.

Yang Y, Ogawa Y, Hedstrom KL, Rasband MN (2007) betaIV spectrin is recruited to axon initial segments and nodes of Ranvier by ankyrinG. J Cell Biol 176:509-519.

Yu FH, Mantegazza M, Westenbroek RE, Robbins CA, Kalume F, Burton KA, Spain WJ, McKnight GS, Scheuer T, Catterall WA (2006) Reduced sodium current in GABAergic interneurons in a mouse model of severe myoclonic epilepsy in infancy. Nat Neurosci 9:1142-1149. 